\title{
Emergency contraception
}

\author{
A few days rather than a few hours to act
}

"Morning after" - when used to describe a form of contraception-confuses both doctors and patients by implying the need to start treatment within a few hours. "Postcoital" is similarly misleading. The Family Planning Association prefers the term "emergency contraception," by which it means contraception used after intercourse but before implantation. This gives the patient and her doctor a few days rather than a few hours to act. Two methods exist: the Yuzpe method and the intrauterine contraceptive device (IUCD).

The Yuzpe method must begin within 72 hours of unprotected sexual intercourse. It entails taking four tablets of ethinyloestradiol $50 \mu \mathrm{g}$ and norgestrel $500 \mu \mathrm{g}$ : two tablets immediately and two 12 hours later. ${ }^{2}$ Overall failure rates are about $2-3 \%,{ }^{3}$ with perhaps twice this failure rate when used at mid-cycle. ${ }^{+}$This compares with a risk of pregnancy of about $20 \%$ when unprotected intercourse occurs at mid-cycle, $30 \%$ at ovulation, and $0-10 \%$ at other times. ${ }^{5}$ The Yuzpe method should not be used when absolute contraindications to oestrogens are present. (These include pregnancy, crescendo angina, transient ischaemic attacks, liver disease, undiagnosed genital tract bleeding, and a history of thromboembolism. Some absolute contraindications to long term use-such as breast cancer and arterial disease-are not contraindications for short term use.)

The Yuzpe method's main disadvantage is nausea and vomiting; another disadvantage is the risk of ectopic pregnancy when the method fails.

The IUCD may be inserted up to five days after unprotected intercourse and fails in less than $1 \%$ of cases. ${ }^{6}$ Although contraindicated if the patient has a history or high risk of ectopic pregnancy, an IUCD may be fitted in selected cases, providing that it is removed after the next period. Other contraindications to its use-pelvic infection or recent exposure to sexually transmitted infection - may be dealt with when the IUCD is inserted. An advantage of the IUCD is that it can remain in place as the long term method of contraception.

Women most commonly seek emergency contraception either because no contraception was used at the time of intercourse or because their chosen method-usually the sheath or cap-has failed. ${ }^{7}$ The need for emergency contraception is not the prerogative of the young and feckless: women present from all age groups and walks of life. ${ }^{8}$ More awareness of emergency contraception could substantially reduce the numbers of abortions - perhaps by a third if the findings of a study in Tower Hamlets were repeated nationally. In this study of women attending an abortion service nearly half would have been suitable for emergency contraception, and $80 \%$ said that they would have used it had they known of it.

What could increase the use of emergency contraception? Firstly, society needs to accept that unprotected sexual intercourse occurs and will continue to occur regardless of its attitude towards such activity. Secondly, there should be open access to emergency contraception, with district health authorities ensuring a choice of clinics in general practice, hospitals, and the community. Access should be available, somewhere, seven days a week. ${ }^{8}$ Whoever coordinates district family planning and abortion services should be responsible for establishing emergency contraception services, which should receive extensive local publicity. Thirdly, all couples using contraception, especially those relying on barrier methods, should know about emergency contraception. And lastly, if the full potential of emergency contraception is to be realised then current reductions in community family planning clinics and patchy training of general practitioners and hospital doctors in contraceptive practice need urgent review.

Honorary Senior Lecturer in Human Sexuality,

F C READER

St George's Hospital Medical School,

London SW 17 ORE

1 Burton R, Savage W, Reader F. The "morning after pill": is this the wrong name for it? British Journal of Family Planning 1990;15:119-21.

Yuzpe AA. Postcoital hormonal contraception: users, abusers, and abuses. Int $f$ Gynaecol Obstet 1977;15:133-6.

3 Yuzpe AA, Smith RP, Rademaker AW. A multicenter clinical investigation employing ethinyl estradiol combined with dl-norgestrel as a postcoital contraceptive agent. Fertil Steril 1982;37: 508-13.

4 Rowlands S, Guillebaud J, Bounds W, et al. Side effects of danazol compared with an ethinyloestradiol/norgestrel combination when used for postcoital contraception. Contraception 1983;27:39-49.

Tietze C. Probability of pregnancy resulting from a single unprotected coitus. Fertil Steril 1960;11:485-8.

Friedman EHJ, Rowley DEM. Postcoital contraception-a two year evaluation service. British Journal of Family Planning 1987;13:139-44.

Yuzpe AA, Lancee WJ. Ethinylestradiol and dl-norgestrel as a postcoital contraceptive. Fertil Steril 1977;28:932-6.

8 Bromwich PD, Parsons AD. The establishment of a postcoital contraception service. British Journal of Family Planning 1982;8:16-9.
General practitioners are ideally placed to counsel their patients on the risks of acquiring HIV. Although many are keen to care for HIV positive patients and help prevent the spread of the virus, ${ }^{1}$ few discuss the subject with their patients. One study estimated that HIV is mentioned in only one in 220 consultations, $^{2}$ and where discussion of risk behaviour and HIV could logically be expected - accompanying general practitioners' contraceptive advice-it seems largely absent. More therefore needs to be done to help general practitioners to help those who are at risk from HIV. Enabling them to prescribe condoms on FP10s would be a start. ${ }^{3}$
Latex condoms prevent the transmission of many sexually transmitted diseases. ${ }^{+}$Mechanical models have confirmed their effectiveness as physical and chemical barriers against HIV, ${ }^{56}$ and nonoxinol 9 , incorporated in the lubricant of some condoms, may be useful if this barrier breaks, by inactivating HIV. ${ }^{78}$

But condoms have many negative associations in Western culture. They are associated with furtive sexual activity in the adolescent and sexual incontinence in the adult. They may symbolise a relationship in which something vital is held back, and suggesting their use to prevent infection may be 
understood by the other partner as implying that he or she is polluted. ${ }^{9}$ As well as prejudicing potential users, this negative symbolism affects governments and health care planners and providers. Prejudice against condoms is only part of the problem: condoms must be used correctly, and many men lack instruction or skill in their use. ${ }^{10}$ Some may use them only when they perceive that the risk of infection is high.

Epidemiological trends in the United States (AIDS is set to become one of the five leading causes of death in women between 15 and 44, disproportionately affecting the poorest) illustrate the need for preventive measures being freely available from the health care providers most likely to be consulted by those at risk." As well as providing free condoms, these providers need skills in introducing the topic into consultations, countering the negative associations of condom use, and teaching how to discuss using condoms with a sexual partner.

Financial constraints on health authorities in Britain are forcing many family planning clinics to close, restricting access to free condoms. Although health authorities may use some of their earmarked AIDS funds to provide free condoms for distribution by general practitioners, other calls on these funds-genitourinary medical services, services for drug misusers, the care of people with HIV infection, and other local preventive measures-make this unlikely, particularly when other drugs and supplies prescribed by general practitioners are separately funded.

No matter how much information on AIDS is disseminated by a responsible media, resources are wasted if people are not helped to act on the information they have acquired. They may know about safer sex, and even believe that it is worth while and sensible, yet fail to adopt it. ${ }^{12}$ Finding that condoms are not available from their general practitioner (who seems reticent to discuss sexual behaviour ${ }^{13.14}$ ) may hinder patients' ability to make use of what they have learnt about HIV.
Difficulties about discussing the need for safe sex with a partner may be compounded.

Rightly or wrongly, the outcome of a general practice consultation is heavily influenced by what can be prescribed. If general practitioners could prescribe condoms on FP10s, and this was well known, it might substantially change their consultations, not only with women requiring contraception but also with sexually active men. With condoms costing something like $£ 12$ for a hundred, this could prove expensive for the NHS, especially as some of the cost would be incurred by those using condoms for contraception who were not at increased risk of acquiring HIV. These costs will, however, seem small when compared with the costs of an HIV epidemic.

General Practitioner, Gill Street Health Centre,

DAVID KIRBY

Limehouse, London E14 8HQ

1 Anderson P, Mayon-White R. General practitioners and management of infection with HIV. BMJ 1988;296:535-7.

2 Gallagher M, Foy CJW, Rhodes TJ, et al. HIV infection and AIDS in England and Wales; general practitioners' workloads and contact with patients. British fournal of General Practice 1990;40 $154-7$

3 Working Party of the Royal College of General Practitioners. Human immunodeficiency virus infection and the acquired immune deficiency syndrome in general practice. $\mathcal{F} R$ Coll Gen Pract 1988;38:219-25.

4 Stone KM, Grimes DA, Magder LS. Personal protection against sexually transmitted diseases. Am f Obstet Gynecol 1986;155:180-8.

5 Rietmeijer CAM, Krebs JW, Feorino PM, Judson FN. Condoms as physical and chemical barriers against human immunodeficiency virus. F A.MA 1988;259:1851-3.

6 Van De Perre P, Jacobs D, Sprecher-Goldberger S. The latex condom: an efficient barrier against sexual transmission of AIDS-related virus AIDS 1987;1:49-5I.

7 Hicks DR, Martin LS, Getchell JP, et al. Inactivation of HTLV-III/LAV-infected cultures of normal human lymphocytes by nonoxynol-9 in vitro. Lancet 1985;ii:1422-3.

8 Malkovsky M, Newall A, Dalgliesh AG. Inactivation of HIV by nonoxynol-9. Lancet 1988;i:645.

9 Valdiserri RO. Preventing AIDS - the design of effective programs. New Brunswick: Rutgers University Press, 1989.

10 Department of Health. Handbook of contraceptive practice. London: Department of Health, 1990

11 Anonymous. AIDS in women-United States. MMWR 1990;39:845-6.

12 Hays RB, Kegeles SM, Coates TJ. High HIV risk taking among young gay men. AIDS 1990;4: Hays RB,
$901-3$.

13 Naji SA, Russell IT, Foy CJW. HIV Infection and Scottish general practice: knowledge and attitudes. $\mathcal{F} R$ Coll Gen Pract 1989;39:284-8.

14 Milne RIG, Keen SM. Are general practitioners ready to prevent the spread of HIV? BMF 1988;296:535-7.

\section{Health education and ethnic minorities}

\section{Needs may differ, the techniques don't}

Health education officers in inner cities are often asked by doctors, nurses, and other health professionals for help with the "problem" of providing health education for ethnic minorities. This is an unfortunate attitude as health promotion is based on the same broad principles whatever the community - what changes are the needs and how they may be met. Indeed, some communities may have a high uptake of some health promotional activities - for example, in one Turkish speaking community, uptake of BCG and diphtheria, pertussis, tetanus, and polio immunisations was at least one quarter higher than the average for the population (R Atun, $S$ Jenkins, unpublished observations). Nevertheless, health professionals are probably less likely to take up all opportunities for health promotion with patients of a different culture from themselves, especially if preferred languages are different.

Defining needs is the first step in health promotion, with those defined by the community not necessarily coinciding with those defined by the health professionals. ${ }^{12}$ Imposing trained outsiders' views on a community may be resented and rejected, and community members must participate in deciding which topics should be tackled. The dangers of racism and stereotyping in deciding what to campaign about should be acknowledged.
Once the target for health promotion has been determined - for example, the low uptake of cervical smear tests in "at risk Asian women" in Leicester (p 833) ${ }^{3}$-the methods of carrying out the campaign must be decided. Here, much research, not only with ethnic minorities but also with the whole population, needs to be carried out. Personal intervention may be more effective than printed material and is likely to be even more so if carried out by a trained member of the relevant ethnic minority. ${ }^{+5}$ Videos and personal intervention by trained members of the target community may give the best results with groups that are hard to reach.

For doctors and nurses who include health promotion in their consultations special communication skills (for example, eliciting present behaviour and beliefs and jointly planning change) are useful in promoting healthier behaviour. Where the ethnic group of patient and health professional differs skills in cross cultural consultation should be acquired. ${ }^{5.7}$ These include being aware of differing expectations and how to negotiate them, acknowledging that stereotyping affects the consultation, understanding how accent and language interfere with the consultation, and being able to assist patients whose language differs from the health professional's to express themselves, either directly or through an interpreter. Training in health education and health promotion 